Laura Candian Fraccaro

lauracfraccaro@gmail.com

estre (2010) e doutoranda em História So-

cial da Cultura pela Universidade Estadual de Campinas, com graduação (2009) em História pela mesma universidade.

\section{O acervo do Tribunal de Justiça de São Paulo, Comarca de Campinas}

The collection of São Paulo's Court of Justice, Campinas County
Resumo

O presente texto tem como objetivo fazer uma análise histórica da constituição do fundo do Tribunal de Justiça de São Paulo, Comarca de Campinas, que se encontra sob guarda do Centro de Memória da Universidade Estadual de Campinas (CMU). O referido acervo contém por volta de 50 mil documentos, entre processos judiciais e testamentos e quase duas centenas de livros de registros de assuntos diversos. O reconhecimento da importância de acervos judiciais, como o descrito aqui, está fortemente entrelaçado com os movimentos da história e da historiografia. Nessa breve análise, pretendo demonstrar como o surgimento de novos protagonistas na história fomentou a necessidade de guarda e preservação de documentos, principalmente, os judiciais.

Palavras-chave: Tribunal de Justiça; Processo; Historiografia; História vista de baixo.

\section{Abstract}

This paper aims to make a historical analysis about the Court of São Paulo Fund, Campinas County, which is under custody of Centro de Memória - Unicamp (CMU). This collection contains about 50 thousands of documents, including lawsuits and wills, and almost two hundred books of various subjects records. The recognition of the judicial collections' importance, as described here, is strongly intertwined with the movements of history and historiography. In this brief review, I intend to show how the emergence of new players in the history fostered the need for storage and preservation of documents, especially the judicial ones.

Keywords: Court of justice; Process; Historiography; History from below. 
Não me recordo da primeira vez que entrei no Centro de Memória - Unicamp (CMU), pois foram tantas as visitas que a memória não pôde escolher guardar um dia em particular. Depois de mais de uma década consultando seu acervo, ainda me encontro fasci-

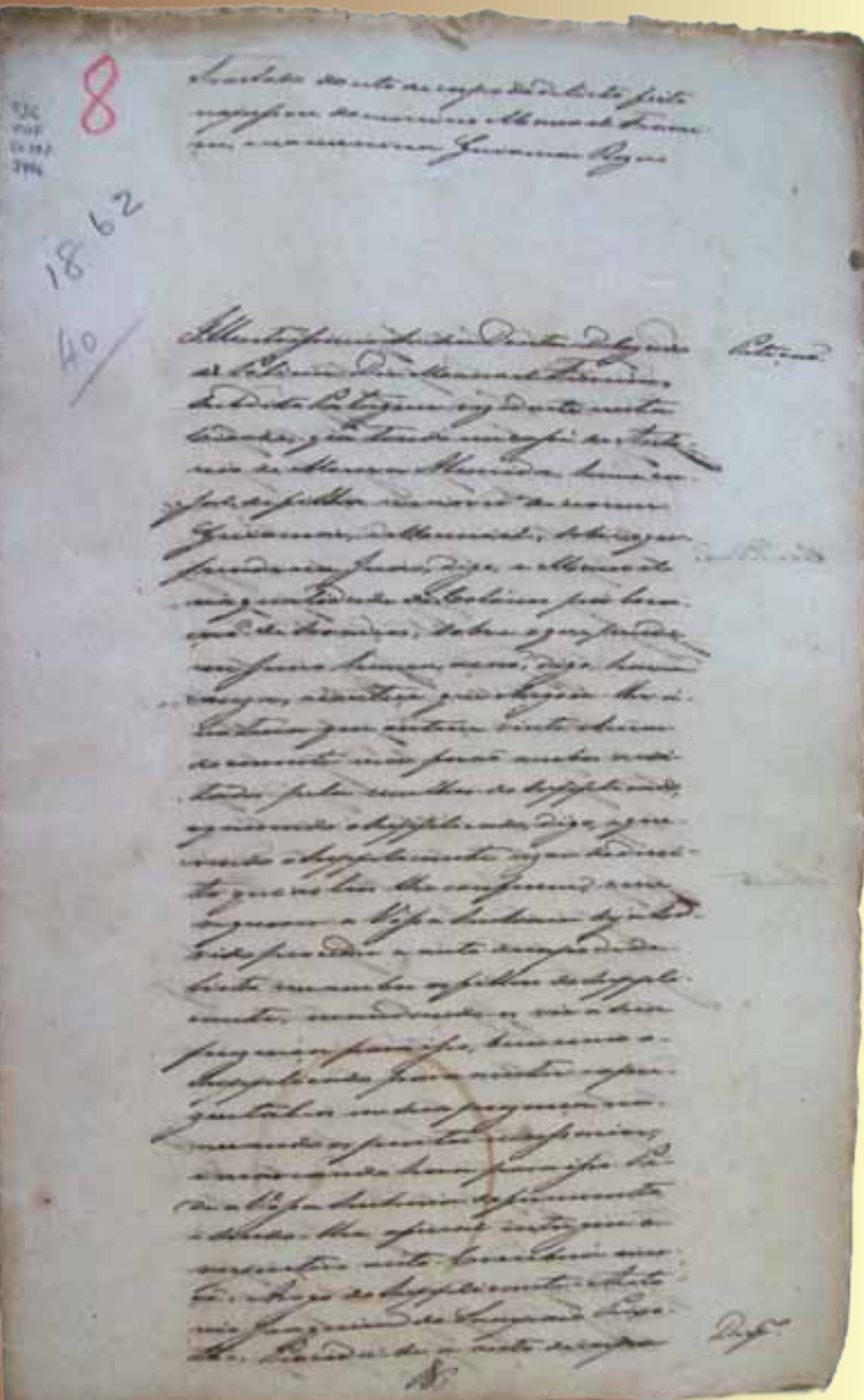

Imagem 1-Pedido de Justificação feito por Salvador Lopes (1807).

Fonte: CMU, TJSP, Comarca de Campinas, Ofício n. 1, Processo n. 9614 nada com as descobertas feitas cotidianamente no fundo do Tribunal de Justiça de São Paulo, Comarca de Campinas.

Com mais de 50 mil processos judiciais, o fundo, chamado pelos pesquisadores de TJC, permite uma infinidade de pesquisas para todo o tipo de pesquisador (historiadores locais, estudantes secundaristas, pós-graduandos e curiosos). Além de processos judiciais criminais, cíveis e comerciais - há livros de registros, testamentos, censo estatístico de órfãos pobres, alguns mapas de fazendas e uma infinidade de outras fontes sobre a cidade de Campinas. Esses registros iniciam-se no final do século XVIII e se estendem até o começo da segunda metade do século XX. Disponíveis quase em sua totalidade para consulta, os processos judiciais foram catalogados e devidamente colocados em um sistema de busca que possibilita a procura através do nome dos envolvidos, o tipo e o ano do processo. 
A criação do acervo do Tribunal de Justiça pelo CMU, que se concretizou no fim da década de 1980, fazia parte de um movimento maior, internacional, de mudança de paradigmas e de objetos da História, que afetaria diretamente a guarda e a preservação de documentos'. Uma infinidade de novos sujeitos - mulheres, negros, pobres, doentes, órfãos- emergia nas pesquisas históricas, tornando os arquivos judiciais impreteríveis ao ofício do historiador. Um dos idealizadores e realizadores da constituição do acervo do Tribunal de Justiça, o professor do Instituto de Filosofia e Ciências Humanas (IFCH/Unicamp), José Roberto do Amaral Lapa (1929-2000), meia década depois da fundação do CMU, iniciava uma ampla pesquisa sobre a cidade de Campinas e seus sujeitos históricos.

E foi assim que procuramos surpreender os momentos desse movimento sequencial em que se processa a transfiguração da cidade. Acompanhamos personagens e atores, nomeados uns tantos, anônimos muitos, uma multidão na verdade, Uns e outros representam seus papéis num espaço, este, sim, o protagonista principal

1 Para uma apreciação mais densa sobre essa mudança, ver Chalhoub (2005). de nossa aventura, a cidade, a cidade de Campinas (LAPA, 2008a, p. 12).

A necessidade de remarcar o "protagonismo principal" da cidade de Campinas, em meio a tantos personagens "nomeados" e "anônimos", só nos assegura a ideia de que a transformação pela qual a cidade passara séculos antes envolvia uma multidão de sujeitos. Esses sujeitos se multiplicariam noutro livro de Lapa, Os excluídos: contribuição à história da pobreza no Brasil.

Neste estudo, procuramos seguir uma terceira via de abordagem: nem os trabaIhadores (operariado) inseridos no sistema de produção ligado à grande lavoura de exportação e ao mercado de trabalho dela decorrente, portanto a força de trabalho organizada, nem os do lumpemproletariado, a marginalidade da qual, entretanto, não foram de todo excluídos, pois vagam também pelo universo que procuramos desvendar. Esse universo, no entanto, é povoado por legiões de desgraçados, excluídos diríamos hoje, que, se não estão inseridos na economia formal e muitas vezes até na informal, não caíram também no submundo (LAPA, 2008b, p. 18).

Essa profusão de sujeitos anônimos, por muitos séculos desprezados pelos 
estudos históricos, raramente deixava registros feitos por suas próprias mãos, como diários ou cartas. Os processos judiciais e testamentos, ambos presentes no acervo, permitem que o historiador entre em contato com a realidade vivida por esses sujeitos e suas impressões sobre diversos temas. Acontecimentos do cotidiano como brigas em bares, bate-bocas entre vizinhos, entre mestres e aprendizes e homicídios, por exemplo, são recorrentes nos registros do acervo do Tribunal de Justiça. A riqueza desses processos já foi muitas vezes assinalada pelos historiadores, sem, no entanto, se absterem de fazer crítica à fonte:

O fundamental em cada história abordada não é descobrir "o que realmente se passou" apesar de como foi indicado, isto ser possível em alguma medida -, e sim tentar compreender como se produzem e se explicam as diferentes versões que os diversos agentes sociais envolvidos apresentam para cada caso. As diferentes versões produzidas são vistas neste contexto como símbolos ou interpretações cujos significados cabem desvendar. Estes significados devem ser buscados nas relações sociais que se repetem sistematicamente entre as várias versões, pois as verdades do historiador são estas relações sistematicamente repetidas (CHALHOUB, 2001, p. 40).

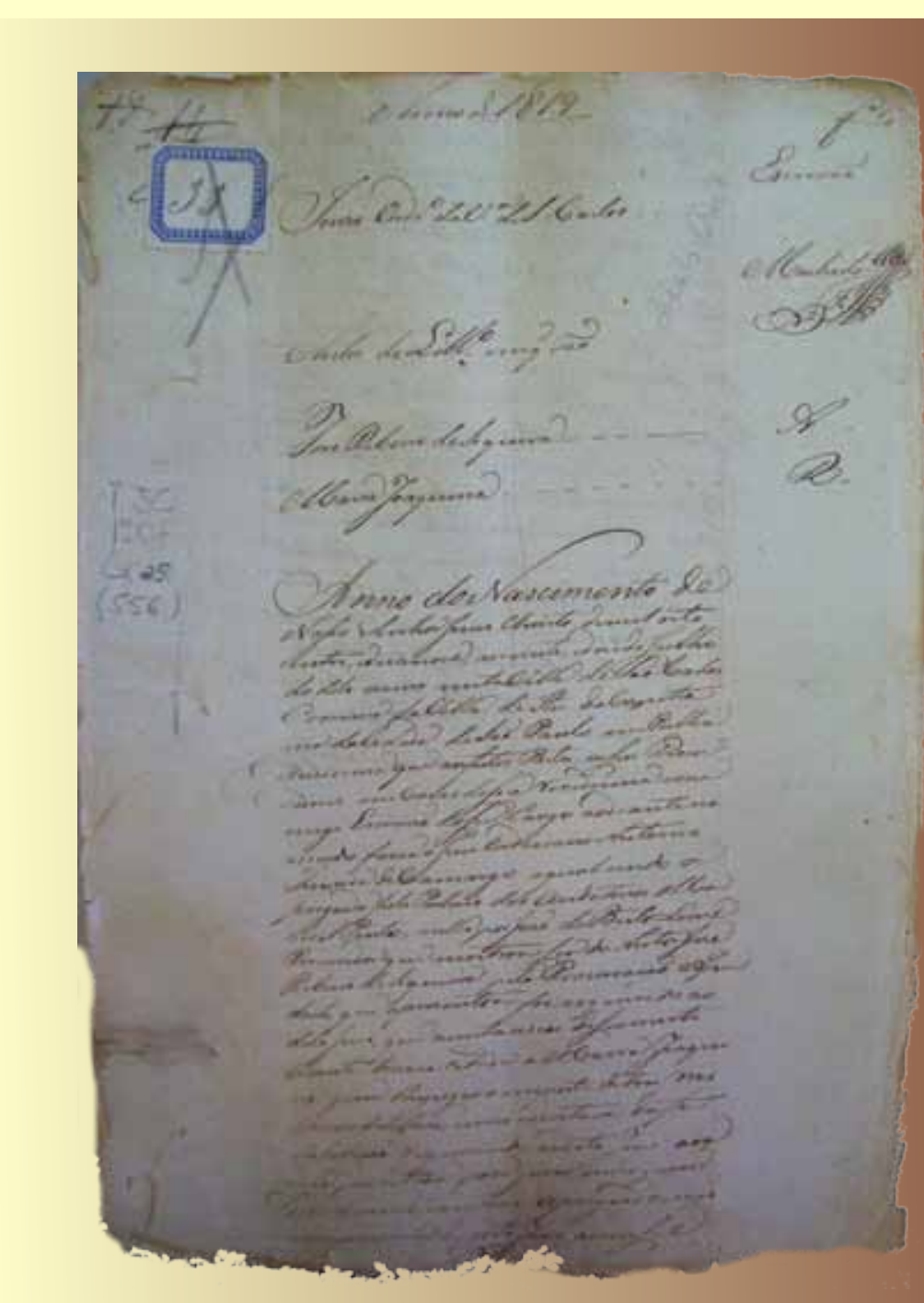

Imagem 2 - Depoimento da testemunha João Manuel de Campos no processo de Força movido por Coronel Gavião contra José Ribeiro (1800).

Fonte: CMU, TJSP, Comarca de Campinas, Ofício n.1, Processo n. 9562.
Detenho-me, aqui, a fazer uma breve descrição de algumas tipologias de processos e suas possíveis aplicações. 
Dentre os processos que tratam de interações do cotidiano, destaco os de Justificação, que são processos, em geral, muito ricos em detalhes sobre os envolvidos e suas relações sociais. A justificação constitui-se em uma petição feita por um indivíduo, ou um grupo de pessoas, que apresenta um acontecimento por meio de argumentos, justificativas, com o objetivo de se "provar uma verdade"2. Entrega-se ao juiz uma petição na qual se explica o que se pede, a razão do pedido e uma sugestão para solucionar o entrave ou uma punição. Apresento duas dessas ações para tornar mais clara a sua definição.

No ano de 1807, Salvador faz um requerimento afirmando que havia trocado seu cavalo por outro e, chegando à Vila de Campinas com sua aquisição, o Padre Vigário tomou-lhe o quadrúpede, dizendo que o animal pertencia-Ihe, mas havia sido furtado. Salvador foi à justiça pedindo que se provasse que o cavalo era de fato do dito Padre e que, se não fosse possível a comprovação, ele deveria receber o

2 No Dicionário Bluteau (1728, p. 179), define-se justificação como "Exibição, ou produção dos títulos, ou testemunhas, em ordem a provar uma verdade". cavalo de volta3. No ano de 1823, moradores do bairro da Santa Cruz afirmavam que Francisca de Paula era "mulher prostituta e meretriz, de vida depravada, e língua sanguinolenta, [que] sem ter casa própria naquele bairro, persegu[ia] os suplicantes" e, se sua conduta fosse provada, ela deveria sair do bairro, conforme uma lei do reino de Portugal4. As testemunhas pouco disseram sobre a vida pessoal da acusada, mas repetidamente afirmaram que era uma ladra contumaz das criações de seus vizinhos 5 . As duas ações, brevemente apresentadas, trazem requerimentos de indivíduos que gostariam de resolver uma situação de uma forma mais simples e rápida. São acontecimentos do cotidiano que não se transformaram em longos processos ou que não envolviam uma quebra aguda das leis, mas discordâncias sobre acontecimentos.

As ações de Justificação oferecem aos pesquisadores um mundo de demandas, conflitos e visões sobre trabalho, saúde, honra, propriedade e uma

3 Centro de Memória - Universidade Estadual de Campinas, Acervo do Tribunal de Justiça de São Paulo, Comarca de Campinas, Processo n. 9614, Ofício n.1.

4 CMU, TJSP, Comarca de Campinas, Processo n. 804, Ofício n.1. 5 Para uma análise mais detalhada sobre esse processo, ver Fraccaro (2012). 
gama variadíssima de temas que a sua nomenclatura não deixa mostrar. A maneira como foram classificadas pelo próprio sistema judicial-chamadas de Justificação - acaba por esconder fontes ricas que não devem passar despercebidas pelos pesquisadores. Assim como as ações de Justificação, os Libelos Cíveis tratam de diversas disputas travadas entre os habitantes de Campinas. Ambas as tipologias são plurais e seus nomes pouco revelam o conteúdo fértil. Olhando mais detaIhadamente, há disputas sobre terras, posses, gados e também de famílias sobre a partilha de seus inventários.

Em minha pesquisa de doutoramento, Estratégias de pequenos agricultores livres de cor perante a expansão dos engenhos de açúcar em Campinas: 1779-1836, utilizo diversos tipos de processos judiciais do acervo do Tribunal de Justiça. A metodologia por mim adotada é a de cruzamento nominativo de fontes, cuja proposta, nesta pesquisa, é seguir, ao longo dos anos e em todo tipo de documentação, os produtores de

6 Pesquisa desenvolvida sob a orientação do Prof. Dr. Robert W. A. Slenes, no Instituto de Filosofia e Ciências Humanas (IFCH/Unicamp), na linha História Social da Cultura, com financiamento da Fundação de Amparo à Pesquisa do Estado de São Paulo (Fapesp). alimentos para que se possa analisar as estratégias traçadas em momentos diferentes da expansão da produção de açúcar e as possibilidades de manutenção da terra?. Utilizo, portanto, o banco de dados do acervo que oferece a busca por nomes dos envolvidos sem precisar limitar a busca pelo tipo da ação, acessando, assim, todo tipo de processo que uma pessoa possa ter sido uma das partes (autor, acusado, suplicante, suplicado, réu).

De forma geral, analiso os processos relativos à disputa de terras e, a partir de nova busca no banco de dados com os nomes dos envolvidos, encontro outros processos para saber quem eram e que fim levaram depois da disputa inicial. Poderia ter escolhido analisar sistematicamente apenas os processos sobre terras, porém acredito que o uso circunscrito de fontes pode ocultar possíveis relações que os indivíduos construíram ao longo da vida. Ao seguir os sujeitos em outras documentações e ao longo de toda a sua vida, desde a paróquia na qual foram batizados por seus pais e padrinhos até seus inventários, pode-se re-

7 Cf. Macfarlane (1977). 
cuperar toda uma rede de conhecidos que são acionados em uma situação de necessidade, perigo, celebração, amizade...

Se me detivesse apenas nos processos que tratam de disputa sobre uma propriedade, chamados de processos de Força Velha ou Nova, não teria notado uma rede de posseiros e pequenos agricultores que engenhosamente invadiram a sesmaria do Coronel Joaquim José da Costa Gavião. Em pouco mais de dois anos, o sesmeiro moveu dez processos tentando retirar os invasores de sua terrå. Ao buscar detaIhes, dentro dos próprios processos e em outros registros, sobre os agricultores que invadiram a sesmaria de Gavião, foi possível descobrir que a maioria começou a roçar no mesmo mês e ano: agosto de 1799. Todos decidiram começar a roça plantando milho. A entrada orquestrada na sesmaria, a seleção do cultivo e o trabalho em grupo adquirem significados mais profundos do que se vistos caso a caso. Esses homens e mulheres não vagavam a esmo, procurando qualquer terra para iniciar sua roça. Pelo contrário, havia

8 CMU, TJSP, Campinas, Ofício n. 1, Processos n. 9546, 9562, 9557, 9544, 019, 021, 9567, 9543, 9564, 029, 030. planejamento, que só pode ser percebido pela pesquisa quando os processos foram analisados em conjunto e cruzados com outros registros.

A escolha de iniciar a roça com milho em uma posse vulnerável, que podia ser terminada por vias judiciais, pode ser explicada pelos usos do vegetal e seu tempo de colheita. Milho é conhecido como um grão de múltiplas funções, sendo essencial para a estratégia desses posseiros. Além de alimentar pessoas, pode servir a animais e, ainda, pode ser colhido num prazo de três meses. Para aqueles que pretendiam entrar no mercado local, o milho era uma forma segura de fazer esse investimento, pois, se o preço caísse muito, a colheita poderia servir ainda para alimentação do grupo familiar e engorda de animais, o que era impossível com a cana, por exemplo. A colheita rápida renderia ainda frutos, mesmo que houvesse uma expulsão desses agricultores.

Não é possível, no entanto, dizer, sem dúvida, que adentraram todos juntos e de forma articulada nas terras de Gavião, mas os registros indicam que eles sabiam quão difícil seria começar 
uma roça sozinhos. De acordo com as testemunhas, esses posseiros contaram com ajuda de camaradas, filhos e genros para desmatar e iniciar a sua roça. Movimentar-se junto à família ou outro grupo parece ter sido vital a esses pequenos agricultores.

Alguns desses posseiros deixaram outros registros que sobreviveram até os dias de hoje, como Bento e Ana, cujos inventários pude consultar no CMU. Através das informações dessa fonte e dos maços de população, é possível

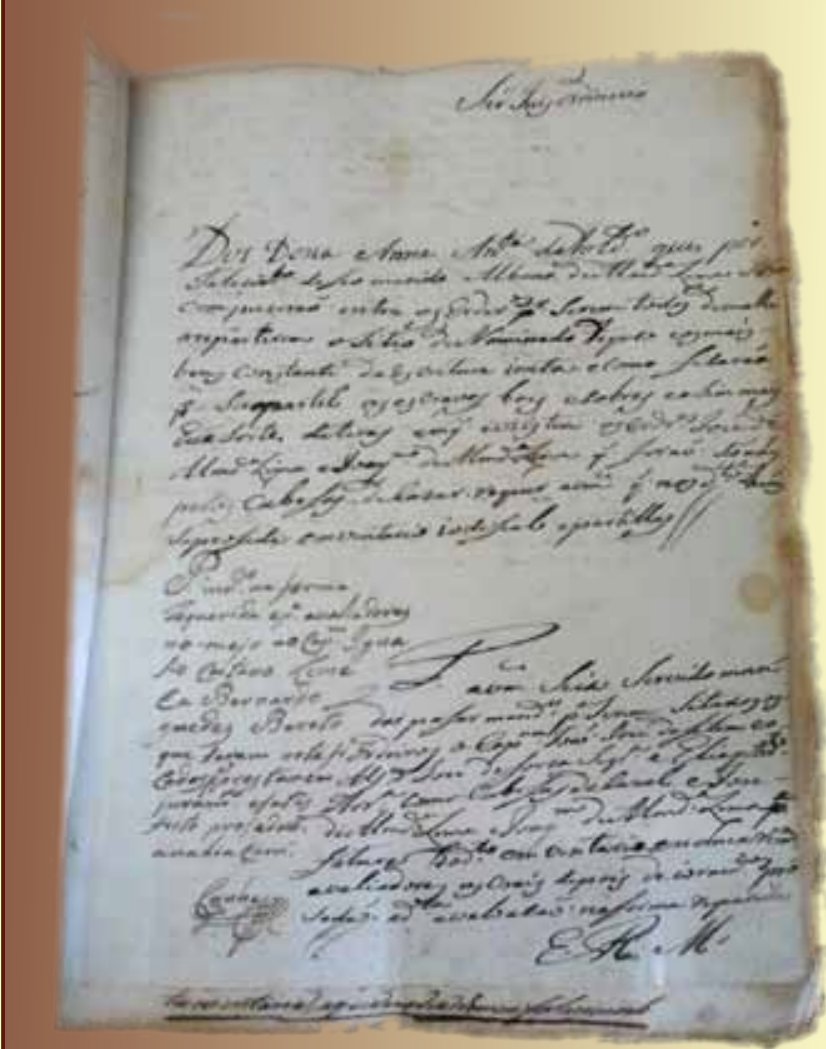

Imagem 3-Inventário de Bento Lopes, que teve como inventariante Teodoro Leme (1839).

Fonte: CMU, TJSP, Comarca de Campinas, Ofício n.1, Processo n. 2061 afirmar que Bento viveu junto no mesmo domicílio com seus filhos e filhas, netos e seus respectivos cônjuges, o que explicaria algumas casinhas pequenas e muito humildes listadas no inventário de sua esposa. Apesar de ter sido expedida a ordem para sua retirada da posse, Bento e sua família continuaram morando no mesmo bairro.

Além de viverem juntos, eles compartilhavam algumas dívidas. Bento pediu, de acordo com o inventário de sua esposa, que um de seus genros devolvesse uma quantia que Bento havia emprestado para quitar dívidas de impostos. Em outro ponto do inventário, ele informou ao juiz que tinha mais empréstimos e dívidas do que a venda de sua terra poderia pagar, e ainda afirmou que seu filho mais velho tinha se tornado o arrimo da família, ajudando-o. Bento estava com quase setenta anos e qualquer auxílio seria bem-vindo.

Bento assegurou-se de ter, próximo de si, sua família e agregados. Desde

9 CMU, TJSP, Campinas, Inventário de Bento Lopes, Processo n. 2061, Ofício n. 1, Ano 1837; Inventário de Ana Cóis, Processo n. 475, Ofício n. 1, Ano 1817; Arquivo do Estado de São Paulo, Maços de População, Campinas, 1816, p. 43 (no qual se encontra o domicílio chefiado por Bento, que contava com a presença de outras dezesseis pessoas, entre herdeiros e agregados). 
o momento que adentrou as terras de Gavião, escolheu um cultivo seguro para iniciar sua roça, porém terminou a vida com poucos pertences e endividado. O que teria acontecido na vida de Bento e de outros pequenos agricultores que os impossibilitou de ascender socialmente? A falta de uma propriedade legal teria grande peso para suas trajetórias? O quanto a expulsão das terras adentradas teria influenciado as suas vidas e as de seus familiares? Como competiram com esses grandes sesmeiros e donos de plantéis de açúcar? Essas são algumas das questões que pretendo responder com a minha pesquisa e cujas respostas acredito estarem no acervo do Tribunal de Justiça da Comarca de Campinas.

O acervo do Tribunal de Justiça permite aos pesquisadores o encontro de sujeitos "anônimos" e "nomeados" e, por guardar processos judiciais, o conflito fica sempre à vista, destacado na superfície. Cabe aos historiadores encontrar as camadas inferiores e colocar esses sujeitos inseridos na sociedade, em seus grupos familiares e de solidariedade.

\section{Dados sobre o fundo:}

Título: Tribunal de Justiça de São Paulo, Comarca de Campinas.

\section{Período de acumulação: $1793-1966$}

Procedência: Documentos doados, sob custódia, pelo Tribunal de Justiça do Estado de São Paulo.

Âmbito e conteúdo: Conjunto documental diverso produzido pelo Tribunal de Justiça do Estado de São Paulo.

Composição: Documentos textuais e iconográficos

Especificação da documentação: Mais de 50 mil documentos (processos), 196 livros de registros e 386 testamentos avulsos.

Conteúdo: Processos cíveis, comerciais e criminais, como, por exemplo, inventários, testamentos, execuções fiscais, Forças, injúrias verbais, inquirição de testemunhas, despejo, acidentes de trabalho, tutela, apreensão de menores, ações de liberdade e homicídio. 


\section{Referências}

BLUTEAU, Raphael. Vocabulario portuguez \& latino. Coimbra: Collegio das Artes da Companhia de Jesus, 1712 - 1728. v. 4. Disponível em: <http://dicionarios.bbm.usp.br/pt-br/dicionario/edicao/1>. Acesso em: 1 set. 2016.

CHALHOUB, Sidney. Trabalho, Iare botequim. Campinas: Editora da Unicamp, 2001.

. O Conhecimento da História, o Direito à Memória e os Arquivos Judiciais. In: Curso de Formação de Multiplicadores em Políticas de Resgate, Preservação, Conservação e Restauração do Patrimônio Histórico da Justiça do Trabalho no Rio Crande do Sul. Porto Alegre: Memorial do TRT $4^{\text {a }}$ Região, 2005.

FRACCARO, Laura C. Vidas em liberdade: pequenos agricultores em Campinas, 1800-1850. 2012. Dissertação (Mestrado em História Social) - Universidade Estadual de Campinas, Campinas. 2012.

LAPA, José Roberto do Amaral. Os Cantos e os antros: Campinas: 1850-1900. São Paulo: Editora da USP; Campinas: Editora da Unicamp, 2008a.

. Os excluídos: contribuição à história da pobreza no Brasil. Campinas: Editora da Unicamp, 2008b.

MACFARLANE, Alan. Reconstructing Historical Communities. London: Cambridge University Press, 1977. 